\title{
BMJ Open Effect of alcohol consumption on haemoglobin level among non-pregnant reproductive age women in Ethiopia: a cross-sectional secondary data analysis of the 2016 Ethiopian Demographic Health Survey
}

\author{
Gedefaw Diress (D) , ${ }^{1}$ Melese Linger Endalifer (D) ${ }^{2}$
}

To cite: Diress G, Endalifer ML. Effect of alcohol consumption on haemoglobin level among non-pregnant reproductive age women in Ethiopia: a cross-sectional secondary data analysis of the 2016 Ethiopian Demographic Health Survey. BMJ Open 2022;12:e046458. doi:10.1136/ bmjopen-2020-046458

- Prepublication history for this paper is available online To view these files, please visit the journal online (http://dx.doi org/10.1136/bmjopen-2020046458).

Received 30 0ctober 2020 Accepted 11 July 2021
Check for updates

(C) Author(s) (or their employer(s)) 2022. Re-use permitted under CC BY-NC. No commercial re-use. See rights and permissions. Published by BMJ.

${ }^{1}$ Public Health, Woldia University, Woldia, Ethiopia

${ }^{2}$ Midwifery, Woldia University, Woldia, Ethiopia

Correspondence to

Gedefaw Diress;

gedefawdiress@gmail.com

\section{ABSTRACT}

Objective The aim of this study was to assess the effect of alcohol consumption on haemoglobin levels among non-pregnant reproductive age women using national representative data.

Method A secondary data analysis was conducted using data from the 2016 Ethiopia Demographic and Health Survey. The main outcome of interest was anaemia defined as a haemoglobin value $<12 \mathrm{~g} /$ which was measured using HemoCue, and adjusted for both altitude and smoking status. The main exposure variable was alcohol consumption. Both multivariable logistic regression and generalised linear model were employed to assess the association between alcohol consumption and anaemia and to compare the mean of haemoglobin between the non-drinkers and three alcohol consumption frequency categories, respectively, after adjusting for the potential confounders.

Result In the current analysis, a total of 13436 nonpregnant women were included. The overall prevalence of anaemia among non-pregnant women was $23.2 \%$ of which $17.9 \%$ were mildly anaemic, $4.6 \%$ were moderately anaemic and $0.7 \%$ were severely anaemic. There was a significant negative association between anaemia and respondents' history and frequency of alcohol consumption in the pooled sample. Among non-pregnant women, the odds of having anaemia were decreased with a history of alcohol drinking (adjusted OR (AOR) $=0.32$ (95\% Cl: 0.214 to 0.394$))$. Women who drunk alcohol less than once a week ((AOR=0.54 (95\% Cl: 0.31 to 0.94), those who drunk alcohol at least once a week (AOR=0.50 (95\% Cl: 0.28 to 0.88$)$ ) and who drunk alcohol almost every day in the last 12 months ( $\mathrm{AOR}=0.42$ (95\% Cl: 0.21 to 0.81$)$ ) had significantly lower odds of having anaemia than women who had not ever taken a drink that contain alcohol. Conclusion This study showed that nearly a quarter of non-pregnant women in Ethiopia were found to be anaemic. Alcohol consumption increases haemoglobin concentration. Further cohort or experimental studies are therefore needed to further assess the relationship between alcohol consumption and haemoglobin level among Ethiopian populations.

\section{Strengths and limitations of this study}

- Used large population-based data with a large sample size, which is representative of all regions of the country.

- As cross-sectional data were used, we cannot assign causality.

- Estimation of alcohol consumption was entirely on self-reporting which might result in social desirability biases and may have been subject to under-reporting.

- The Ethiopia Demographic and Health Survey did not incorporate important behavioural factors (dietary intake, physical activity)

\section{BACKGROUND}

Anaemia is a global health problem that affects one-quarter of the world's population. ${ }^{1}$ The prevalence of anaemia has gradually decreased in the developed countries, but it still remains a major public health problem in most of the developing countries particularly in Africa. ${ }^{2}$ Ethiopia is a country with the highest prevalence of anaemia ranges from $17 \%$ to $52.3 \% .^{2-5}$ Currently, reproductive-age women were disproportionally affected groups by anaemia, making it a global public health problem. ${ }^{1}$

Globally, the prevalence of anaemia is $30 \%$ in non-pregnant women (15-49 years). ${ }^{6}$ Previous studies reported that half of the anaemic mothers during pregnancy start at the time of conception. ${ }^{78}$ Low haemoglobin level and anaemia before pregnancy has been shown to increase the risk of perinatal death, low birth weight, preterm delivery and maternal mortality. ${ }^{9}$ Hence, reducing anaemia in women of reproductive age is considered an essential part of improving the 
health of a woman, and WHO has set a global target of achieving a $50 \%$ reduction of anaemia among women of reproductive age by $2025 .^{10}$ The recommended policies targeted at prevention and reduction of anaemia are mainly focused on the modifiable risk factors such as lifestyles, behavioural and nutritional factors. ${ }^{11}{ }^{12}$ Although there is no concrete evidence, excessive alcohol consumption might be one of the behavioural factors contributing to a higher prevalence of anaemia. ${ }^{12}$ Nowadays, alcohol consumption is also one of the major public health problems in many countries. ${ }^{13}$ It is associated with various chronic medical conditions and responsible for causing about 2.5 million deaths per year and $5 \%$ of all women deaths globally. ${ }^{13-16}$

An association between alcohol consumption and iron overload would be clinically important because alcohol and iron are believed to have synergistic hepatotoxic effects. ${ }^{1718}$ Besides, understanding the effect of alcohol drinking on anaemia is crucial for the development of evidence-based interventions to reduce the anaemia burden in Ethiopia. The association between excessive alcohol consumption and haemoglobin concentration among patients with chronic alcoholism has been well described. ${ }^{19}{ }^{20}$ In contrast, only few studies have investigated the effects of mild or moderate alcohol consumption among the general population. ${ }^{21-23}$ Most importantly, these few studies had inconsistent and conflicting results. Some studies in different parts of the world including Ethiopia identified alcohol drinking as risk factors for anaemia. ${ }^{24-27}$ On the other hand, studies in Tanzania, ${ }^{23}$ $\mathrm{USA}^{22}$ and Denmark ${ }^{28}$ showed that alcoholic beverage consumption increases haemoglobin levels and suggested that moderate consumption of alcohol has a beneficial effect to reduce the prevalence of iron deficiency anaemia.

Furthermore, the majority of previous studies conducted in Ethiopia were restricted to pregnant or lactating women and women living with HIV infection. ${ }^{29-31}$ In addition, almost all of the previous studies were conducted in specific geographical areas that lacked national representation. ${ }^{32-35}$ Therefore, the objective of this study was to evaluate alcohol consumption on haemoglobin concentrations in non-pregnant women using nationally representative Ethiopia Demographic and Health Survey (EDHS) data to inform policymakers.

\section{METHODS AND MATERIALS}

This analysis used secondary data from the 2016 EDHS. The sampling frame used for the 2016 EDHS is the Ethiopia Population and Housing Census (PHC), which was conducted in 2007 by the Ethiopia Central Statistical Agency. The census frame is a complete list of 84915 enumeration areas (EAs) created for the 2007 PHC. An EA is a geographical area covering on average 181 households. Administratively, Ethiopia is divided into nine geographical regions and two administrative cities. The 2016 EDHS sample was stratified and selected in two stages. Each region was stratified into urban and rural areas, yielding 21 sampling strata. Samples of EAs were selected independently in each stratum in two stages. In the first stage, a total of 645 EAs (202 in urban areas and 443 in rural areas) were selected with probability proportional to EA size (based on the 2007 PHC) and with independent selection in each sampling stratum. In the second stage of selection, a fixed number of 28 households per cluster were selected with an equal probability systematic selection from the newly created household listing. All women aged 15-49 who were either permanent residents of the selected households or visitors who stayed in the household the night before the survey were eligible to be interviewed. ${ }^{36}$ Data were obtained from the DHS programme website: https://wwwdhsprogramcom. In 2016 EDHS, a total of 15683 reproductive-age women have participated in the survey. However, we restrict our analytical sample to 13636 women reproductive age group after excluding pregnant women and women who had no haemoglobin measurement.

\section{Study population and eligibility criteria}

All non-pregnant women of reproductive age were the study population. In this study, we included women who meet the following criteria; (1) non -pregnant women and (2) women who gave consent to draw a droplet of blood for haemoglobin measurement after reading a consent statement to woman/parent/responsible adult.

\section{Study variables}

\section{Outcome of interest}

The main outcome of interest was anaemia. Based on WHO cut-off levels, non-pregnant women with a haemoglobin value $<12 \mathrm{~g} / \mathrm{dL}$ were considered anaemic. ${ }^{37}$ This variable was used to determine categories of anaemia status described as anaemia (mild, moderate, severe) or normal. In the EDHS 2016, haemoglobin levels of the women were measured using HemoCue, and all haemoglobin values were adjusted for both altitude and smoking status.

\section{Exposure variables}

In this study, the main exposure variable is alcohol drinking (history and frequency of alcohol consumption). In 2016 EDHS, survey respondents were asked 'have you ever taken a drink that contains alcohol?' For this question, two response categories were included: Yes and No.

Survey respondents who responded 'yes' to the above question were also asked, 'how often they drank alcohol in the last 12 months prior to the survey?'. Regarding the frequency of alcohol consumption, four response categories were included: almost every day, at least once a week, less than once a week and none in the last 12 months. However, in this study non-drinker group includes both women who had not ever taken a drink that contains alcohol in a lifetime and who have taken alcohol but none in the last 12 months. 


\section{Covariates}

Age (15-24, 25-34 and 35-49 years), residence (urban and rural), educational status (no education, primary, secondary and higher), region (major, developing and major city administrative), occupation (working or not working outside the home at the time of the survey), ${ }^{38} 39$ marital status (married and not married), wealth index (poor, middle and rich), ${ }^{38}$ media access, body mass index (BMI), number of birth in the last 5 years and access to care and source of drinking water (improved, non-improved and surface water). Previous studies have identified the above variables as determinants of anaemia. Therefore, these variables were selected a priori for inclusion in regression models as potential confounders.

Region was categorised based on the Federal Democratic Republic of Ethiopia government administrative classification (major, developing, and city administrative). Ethiopia is administratively divided into nine regional states and two city administration. However, the Ethiopian government classified nine regional states in to two categories based on economic growth and availability of infrastructure. Oromia, Amhara Tigray and Southern Nation, Nationality and people were classified as developed regional states. Whereas, Afar, Somali, Gambella, Harari and Benishangul-Gumuz were considered as developing regional state. Addis Ababa and Dire Dawa were categorised as city administration. Media exposure was classified based on response to how often respondents read a newspaper, listened to the radio or watched television. Those who responded at least once a week to any of these sources were considered to have access to media. Access to care is defined as having visited a healthcare facility within 12 months of the survey. The source of drinking water is categorised into three groups according to definitions recommended by the WHO/UNICEF Joint Monitoring Programme for Water Supply and Sanitation. ${ }^{40}$ Improved water source includes piped water into dwelling, yard or plot, public tap or standpipe, tube well or borehole, protected spring and protected dug well. Unprotected dug well, unprotected spring, cart with small tank or drum, tanker truck and bottled water were classified as unimproved water sources. Surface water source includes river, dam, lake, pond, stream, canal, irrigation channel and rainwater collection.

\section{Statistical analysis}

Participant characteristics were summarised using frequency and weighted percentage. Multicollinearity between independent variables was cheeked before fitting the final regression model. When two independent variables were found highly correlated, one was dropped.

The anaemia level was first analysed bivariably using logistic regression to estimate unadjusted ORs and $95 \%$ CIs. Thereafter, multivariable logistic regression models were used to calculate the ORs with 95\% CIs for the presence of anaemia by using women who had not ever taken a drink that contains alcohol as the reference group. In the multivariable model, the following variables were adjusted for: age, educational status, religion, marital status, occupation, wealth index, media exposure, chat chewing, BMI, contraceptive use, number of birth in the last 5 years, access to care and source of drinking water.

The goodness of fit of the final logistic model was tested using Hosmer-Lemeshow test at a $p$ value of $>0.05$. Adjusted ORs with 95\% CI were used to measure the association between alcohol consumption and the outcome variable (anaemia). All statistical techniques used a complex sampling design applied in the 2016 EDHS used a two-stage stratified sampling technique. In complex sample design, when SEs, CIs or significance testing is required, it is necessary to consider three pieces of information: the primary sampling unit or cluster variable, the stratification variable and the weight variable. If we assume simple random sampling and independence of observations, the SEs will likely be underestimated and the resulting significance tests invalid.

A Complex Samples General Linear Model (multiple linear regression and analysis of variance (ANOVA)) was also used. The linear regression was to quantify the strength of association between alcohol drinking frequency and haemoglobin level. The regression coefficient describes the average change in the haemoglobin level for the expected difference in alcohol drinking frequency versus a non-drinker group. The coefficient of determination $\left(\mathrm{R}^{2}\right)$, describes the proportion of the variability in the haemoglobin that can be explained by the independent variables. All variables with $p$ value less than 0.2 at bivariate analysis were entered into final regression model. Multicollinearity was checked using variance inflation factor (VIF).

ANOVA is used to compare the mean difference in the levels of haemoglobin between the non-drinkers and the three alcohol consumption frequency categories (almost every day, at least once a week, less than once a week), respectively. ANOVA test showed that there is an overall mean difference between three groups. Therefore, we performed post hoc tests to confirm where the differences occurred between groups. The data met the assumption of homogeneity of variances. Hence we used Tukey's honestly significant difference post hoc test.

\section{Patient and public involvement}

There was no patient and public involvement in this study since we conducted a secondary data analysis based on already available DHS data. For the original project, data were obtained by engaging patients and the public, which was essential since biomarker data such as anaemia, HIV testing and anthropometric measurements were collected

\section{RESULT}

Sociodemographic and household characteristics of nonpregnant women

In the current analysis, a total of 13436 non-pregnant women of reproductive age were included. Of the total women who participated in this analysis, $39.1 \%$ of the 
Table 1 Characteristics of the study sample ( $\mathrm{N}=13436)$

\begin{tabular}{|c|c|c|c|}
\hline Variables & Categories & Number & Weighted \% \\
\hline \multirow[t]{3}{*}{ Age } & $15-24$ & 5452 & 39.1 \\
\hline & $25-34$ & 4230 & 32.9 \\
\hline & $35-49$ & 3754 & 28.0 \\
\hline \multirow[t]{2}{*}{ Residence } & Urban & 4500 & 21.9 \\
\hline & Rural & 8936 & 78.1 \\
\hline \multirow[t]{4}{*}{ Educational status } & No education & 6000 & 47.9 \\
\hline & Primary & 4545 & 35.1 \\
\hline & Secondary & 1911 & 11.5 \\
\hline & Higher & 980 & 5.5 \\
\hline \multirow[t]{2}{*}{ Current occupation } & Not working & 6817 & 49.4 \\
\hline & Working & 6619 & 50.6 \\
\hline \multirow[t]{2}{*}{ Marital status } & Not married & 3800 & 27.1 \\
\hline & Married & 9636 & 72.9 \\
\hline \multirow[t]{3}{*}{ Wealth index } & Poor & 5048 & 34.2 \\
\hline & Middle & 1762 & 19.4 \\
\hline & Rich & 6626 & 46.4 \\
\hline \multirow[t]{3}{*}{ Region } & Major & 6385 & 47.5 \\
\hline & Developing & 4579 & 34.1 \\
\hline & Major city administrative & 2472 & 18.4 \\
\hline \multirow[t]{3}{*}{ Body mass index status } & $<18.5 \mathrm{~kg} / \mathrm{m}^{2}$ & 3343 & 22.3 \\
\hline & $18.5-24.99 \mathrm{~kg} / \mathrm{m}^{2}$ & 8565 & 70.4 \\
\hline & $\geq 25.0 \mathrm{~kg} / \mathrm{m}^{2}$ & 1507 & 7.4 \\
\hline \multirow[t]{3}{*}{ Current contraceptive use } & No contraceptive use & 10303 & 72.3 \\
\hline & Use hormonal contraceptive & 2777 & 25.1 \\
\hline & Use non-hormonal contraceptive & 356 & 2.6 \\
\hline \multirow[t]{4}{*}{ Number of birth in the last 5 years } & No birth & 7363 & 52.4 \\
\hline & One birth & 3617 & 28.8 \\
\hline & Two birth & 2038 & 15.9 \\
\hline & Three or more birth & 418 & 2.8 \\
\hline \multirow[t]{3}{*}{ Source of drinking water } & Improved & 9232 & 64.4 \\
\hline & Unimproved & 868 & 4.4 \\
\hline & Surface water & 3336 & 32.2 \\
\hline
\end{tabular}

women were in the age group of 15-24 years and 78.1\% lived in a rural area. Nearly half $(47.9 \%)$ of women were non-educated and $72.9 \%$ got married. Half of the women had no occupation at the time of the survey. Almost a quarter of women were undernutrition (BMI $<18.5 \mathrm{~kg} /$ $\mathrm{m}^{2}$ ) and $7.4 \%$ were overweight (BMI $\geq 25 \mathrm{~kg} / \mathrm{m}^{2}$ ). From the total, $64.4 \%$ of mothers have an improved source of drinking water (table 1).

\section{Weighted proportion of alcohol drinking and anaemia}

In this study, the weighted proportion of women who had ever taken a drink that contains alcohol was 36.3\% (95\% CI: $33.4 \%$ to $39.2 \%$ ). Of the total women who had ever taken alcohol, $5.6 \%$ of women drink almost every day in the last 12 months, $32.0 \%$ of women drink at least once a week and $59.3 \%$ of women drink less than once a week.

The mean haemoglobin level was $12.8 \mathrm{~g} / \mathrm{dL}$ in women who had not ever taken a drink that contains alcohol and $13.2 \mathrm{~g} / \mathrm{dL}$ in women who had ever taken a drink that contains alcohol $(p, 0.024)$. The overall prevalence of anaemia among non-pregnant women was $23.2 \%$ (95\% CI: $21.6 \%$ to $24.9 \%$ ). The prevalence of anaemia was $25.9 \%$ among women who had not ever taken a drink that contains alcohol and $18.5 \%$ among women who drink alcohol (figure 1).

The prevalence of anaemia among non-pregnant women were varied across different regions in Ethiopia. 


\section{percent}

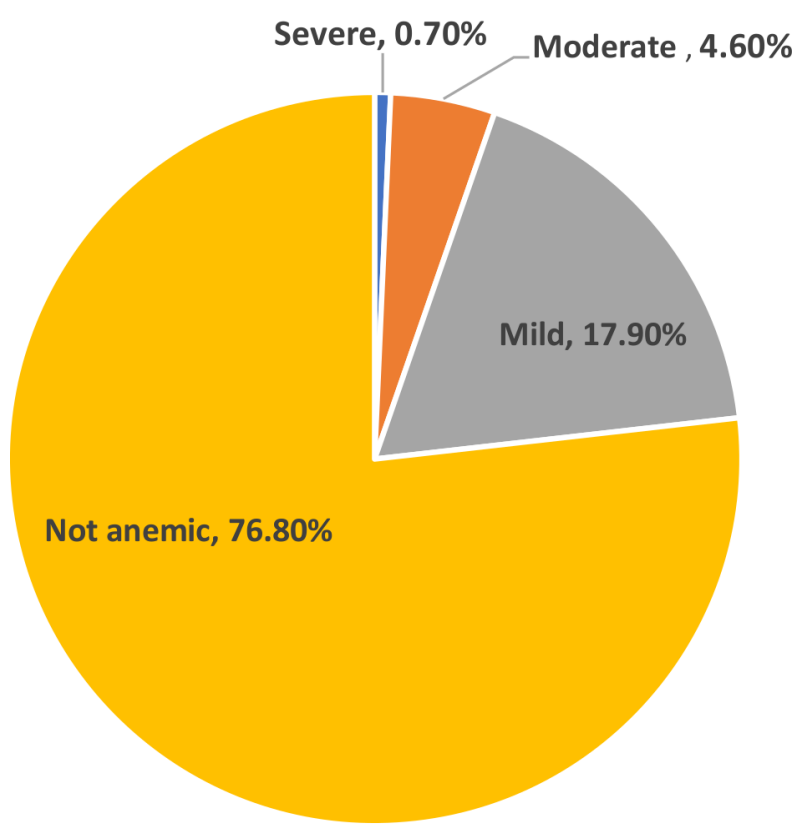

- Severe - Moderate $\|$ Mild $\backsim$ Not anemic Figure 1 Proportion of anaemia among non-pregnant women in Ethiopia.

It was ranged from $15.8 \%$ in Addis Ababa to $59.1 \%$ in the Somali regional state (figure 2).

\section{Association between alcohol drinking and anaemia}

During bivariable logistic analysis, history of alcohol drinking was significantly associated with anaemia (haemoglobin level). Similarly, at the multivariableadjusted model, alcohol drinking is negatively and significantly associated with anaemia after adjusted for other independent variables. The odds of having anaemia was $68 \%$ less likely among women who had ever taken a drink that contains alcohol than women who had not ever taken

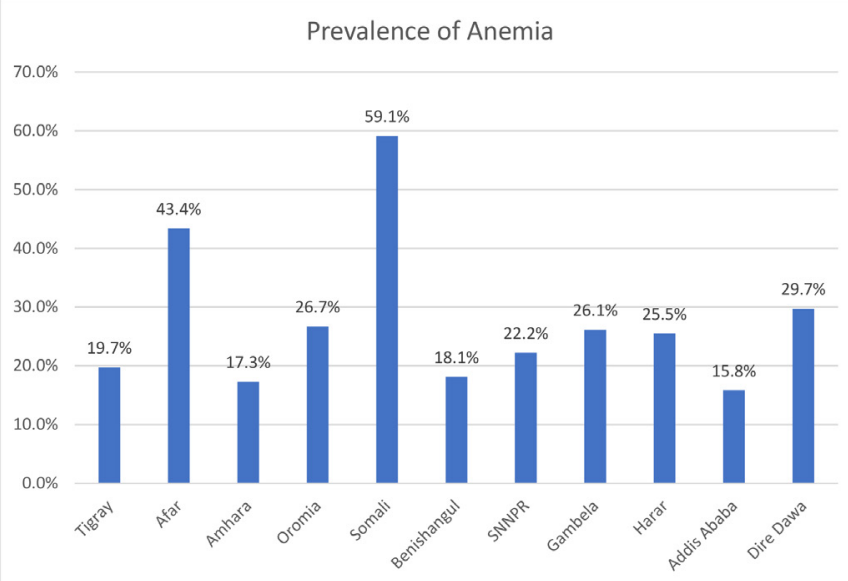

Figure 2 Prevalence of anaemia among non-pregnant women by region, Ethiopia. a drink that contain alcohol (adjusted OR $(\mathrm{AOR})=0.32$ (95\% CI: 0.214 to 0.394$)$ ).

The frequency of alcohol drinking was also significantly associated with the presence of anaemia in both unadjusted and adjusted analyses. The odds of having anaemia is $46 \%$ lower among women who drunk alcohol less than once a week in the last 12 months as compared with women who had not ever taken a drink that contain alcohol (AOR=0.54 (95\% CI: 0.31 to $0.94 ; \mathrm{p}=0.045))$. The odds of having anaemia was $50 \%$ less likely among women who drink alcohol at least once a week as compared with women who had not ever taken a drink that contain alcohol (AOR=0.50 (95\% CI: 0.28 to 0.88$)$ ). The odds of having anaemia is $58 \%$ lower among women who drank alcohol almost every day in the last 12 months as compared with not drinking alcohol (AOR $=0.42(95 \%$ CI: 0.21 to 0.81$)$ ) (table 2 ).

\section{Multivariable linear regression}

In addition to logistic regression, we also employed a multivariable linear regression model to assess the association between alcohol drinking and haemoglobin level. During simple linear regression, frequency of alcohol consumption, age, educational status, marital status, occupation, wealth index, media exposure, BMI, contraceptive, number of birth in the last 5 years, access to care and source of drinking water had $\mathrm{p}$ value less than 0.2 . Therefore, all these variables were entered into final regression model. The result of final regression model showed a positive association between the frequency of alcohol consumption and haemoglobin level. Women who drink alcohol less than once a week will have a haemoglobin level of $0.55 \mathrm{~g} / \mathrm{dL}$ higher than women who had not ever taken a drink that contains alcohol $(\beta=0.55$, 95\% CI: 0.431 to 0.617 ). Similarly, women who drink alcohol almost every day will have a haemoglobin level of $0.68 \mathrm{~g} / \mathrm{dL}$ higher than women who had not ever taken a drink that contains alcohol $(\beta=0.68,95 \%$ CI: 0.645 to 0.713 ) after adjusting for age, educational status, marital status, occupation, wealth index, media exposure, BMI, contraceptive, number of birth in the last 5 years, access to care and source of drinking water (table 3). Multicollinearity was assessed using VIF values. The result showed that all VIF values were below 10 , shows absence of multicollinearity between predictor variables.

\section{ANOVA}

To compare the mean haemoglobin among different categories of alcohol drinking frequency, we used ANOVA (General Linear Model in the complex sample). Mean haemoglobin was $12.79 \mathrm{~g} / \mathrm{dL}$ among non-drinkers. But, it started increasing among women who drink alcohol at least once a week and those who drink almost every day in the last 12 months. In this study, we compared each level of alcohol drinking against the non-drinkers (reference category). There was a significant difference in the mean of haemoglobin for women who drink alcohol almost 
Table 2 Association between alcohol consumption, frequency of alcohol consumption and anaemia among non-pregnant reproductive women in Ethiopia, $(\mathrm{N}=13436)$

\begin{tabular}{|c|c|c|c|c|}
\hline \multirow[b]{3}{*}{ Variable } & & \multicolumn{3}{|l|}{ Anaemia } \\
\hline & & \multicolumn{2}{|l|}{ OR $(95 \% \mathrm{Cl})$} & \multirow[b]{2}{*}{$P$ value } \\
\hline & & Unadjusted analysis & Adjusted analysis* & \\
\hline Alcohol drinking & No & Ref. & Ref. & \\
\hline \multirow{3}{*}{$\begin{array}{l}\text { Frequency of alcohol } \\
\text { consumption in the last } 12 \\
\text { months }\end{array}$} & No alcohol drink & Ref. & Ref. & \\
\hline & At least once a week & $0.64(0.503$ to 0.803$)$ & $0.50(0.28$ to 0.88$)$ & 0.028 \\
\hline & Almost every day & $0.55(0.372$ to 0.800$)$ & $0.42(0.21$ to 0.81$)$ & $<0.001$ \\
\hline
\end{tabular}

*Adjusted for age, educational status, religion, marital status, occupation, wealth index, media exposure, chat chewing, body mass index, contraceptive, number of birth in the last 5 years, access to care and source of drinking water. †Less than once per week includes women who did not drink in the last 12 months. AOR, adjusted OR; COR, crude OR.

every day, at least once and less than once when compared with non-drinker women ( $\mathrm{p}$ value $<0.001$ ) (table 4 ).

The post hoc test result showed that there is significant difference between non-drinkers and all the remaining three groups (less than once a week, at least once a week and almost every day) ( $p$ value $<0.001$ ). However, there is no significant difference between a group who drink less than once a week and drink at least once a week ( $p$ value $=0.912$ ) and there is significant difference between participants who drink alcohol less than a week and who drink almost every day ( $p$ value $=0.959$ ). Similarly, there is no significant difference between the last two groups (at least once a week and almost every day) ( $p$ value $=0.999$ )

\section{DISCUSSION}

Both anaemia and excessive alcohol consumption were a major public concern in Ethiopia. Therefore, evaluating the association between alcohol drinking and anaemia is crucial for evidence-based public health intervention. The finding of this analysis revealed that the frequency of alcohol consumption has a positive significant effect on anaemia (haemoglobin level). The finding is comparable with a study done in Tanzania reported alcoholic beverage consumption was a positive predictor of high haemoglobin concentration. ${ }^{23}$ A nationwide study in the USA also showed that the risks of iron deficiency and iron-deficiency anaemia were approximately $40 \%$ lower among persons who consumed any amount of alcohol compared with non-drinkers. ${ }^{22}$ Similarly, a retrospective cohort study showed that blood haemoglobin concentrations are higher in heavy alcohol consumers than in abstainers. In that study, alcohol consumption of more than seven drinks/week increased the mean haemoglobin by $1.3 \%$ compared with those consuming less than or equal to seven drinks/week. ${ }^{28}$ The first possible justifications for the positive association between alcohol and haemoglobin level might be due to the fact that alcohol enhancing iron absorption. ${ }^{41}{ }^{42}$ Another hypothesis suggests that alcohol-related anaemia reduction is caused at least in part by the iron present in certain alcoholic beverages such as red wine. Similarly, drinking alcohol, which contains folate, reduces the risk of anaemia. ${ }^{43}$ We were unable to test this hypothesis because alcohol consumption was not subdivided according to the type of alcohol in 2016 EDHS. The third possible reason might be related to the type of alcohol consumed in Ethiopia. In the country, especially in rural communities, many peoples consumed homemade traditional alcoholic beverages like tella, tej, areki, borde and shamita ${ }^{44-46}$ on a daily basis. In addition, traditional alcoholic beverages are widely consumed as a prominent part of the local traditions of major social events including public holidays, weddings, funerals and other forms of festivities. These traditional alcoholic beverages are brewed from maize, Dagusa, Teff and sorghum. Dagusa and Teff are a good source of essential minerals especially calcium and iron. ${ }^{47}$

\begin{tabular}{|c|c|c|c|}
\hline Variables & Coefficient $(\beta)^{*}$ & $95 \% \mathrm{Cl}$ & $P$ value \\
\hline Drink alcohol less than once a week & 0.553 & 0.431 to 0.617 & 0.005 \\
\hline Drink alcohol at least once a week & 0.660 & 0.641 to 0.690 & 0.001 \\
\hline Drink alcohol almost every day & 0.684 & 0.645 to 0.713 & 0.002 \\
\hline
\end{tabular}

*Adjusting for age, educational status, marital status, occupation, wealth index, media exposure, body mass index, contraceptive, number of birth in the last 5 years, access to care and source of drinking water. 
Table 4 Comparison of mean haemoglobin level between the frequencies of alcohol consumption with non-alcoholic subjects

Frequency of alcohol consumption in the last 12 months

N (\%)

\begin{tabular}{lllll}
$\begin{array}{l}\text { Non-drinkers } \\
(\mathbf{n}=\mathbf{8 9 9 5}(\mathbf{6 4 . 9} \%))\end{array}$ & $\begin{array}{l}\text { Less than once a week } \\
(\mathbf{n}=\mathbf{2 7 5 8}(\mathbf{2 1 . 5 \% )})\end{array}$ & $\begin{array}{l}\text { At least once a week } \\
(\mathbf{n}=\mathbf{1 4 0 6}(\mathbf{1 1 . 6 \% )})\end{array}$ & $\begin{array}{l}\text { Almost every day } \\
(\mathbf{n}=\mathbf{2 7 7}(\mathbf{2 . 0} \%))\end{array}$ & P value \\
\hline $12.79 \pm 0.049$ & $13.15 \pm 0.049$ & $13.23 \pm 0.068$ & $13.25 \pm 0.102$ & $<0.001$ \\
\end{tabular}

Mean haemoglobin with $12.79 \pm 0.049$

SE

The comparison is based on simple contrasts (compare each level of alcohol drinking against the reference category (non-drinkers)).

This might reduce the risk of anaemia among alcohol drinkers. Besides, borde and shamita are alcoholic beverages with a thick consistency consumed as a meal replacement in some districts of Ethiopia. ${ }^{48} 49$ The final possible justification for this positive association between alcohol consumption and haemoglobin level might be related to the effect of fermentation in traditional alcoholic beverages. Minerals like iron, calcium and zinc are increased fermented foods. ${ }^{5051}$ This is due to the fact that fermentation increases the bioavailability of these minerals due to degradation of oxalates and phytates that complex with minerals thereby reducing their bioavailability. ${ }^{52}$ Therefore, the protective effect of alcohol on anaemia might be due to the iron content of the local alcohol beverage either from the raw material or from the fermentation.

However, the finding of this study is inconsistent with previous studies done in different parts of the world. ${ }^{53-56}$ The difference might be mainly due to the variation in the type of alcohol commonly used in different countries. A study done in India reported that moderate and chronic alcohol consumption decreases haemoglobin levels. ${ }^{54}$ The difference might be due to the difference in sample size and study setting. The previous study was done on a very small sample size $(n=75)$ and it was an institutionalbased study. On the contrary, the current study used large nationally representative data.

The current study has several strengths that include a large nationally representative sample size, availability of detailed data on confounders and standardised, highquality data collection. However, there are several limitations to consider. First, as cross-sectional data were used, we cannot assign causality. Second, estimation of alcohol consumption in 2016 EDHS was entirely on self-reporting which might result in social desirability biases and may have been subject to under-reporting. Some people who drink small amounts of alcohol may report their intake as none that results in the OR to be systematically low.

\section{CONCLUSION}

Nearly one-fourth of non-pregnant women had anaemia. Consumption of any amount of alcohol was associated with a reduction in the risk of anaemia among nonpregnant women. This association suggests that Ethiopian alcoholic beverages may contain iron important to erythropoiesis. Further cohort studies are therefore needed to further assess the relationship between alcohol consumption and haemoglobin level among Ethiopian populations.

Contributors GD: conceived of the presented idea, drafted the manuscript and analysed the data. MLE: discussed the results and commented on the manuscript. All authors read and approved the final manuscript. GD is responsible for the overall content as guarantor.

Funding The authors have not declared a specific grant for this research from any funding agency in the public, commercial or not-for-profit sectors.

Competing interests None declared.

Patient and public involvement Patients and/or the public were not involved in the design, or conduct, or reporting, or dissemination plans of this research.

Patient consent for publication Not applicable.

Provenance and peer review Not commissioned; externally peer reviewed.

Data availability statement Data are available upon reasonable request. The data can be available from the corresponding author on a reasonable request.

Open access This is an open access article distributed in accordance with the Creative Commons Attribution Non Commercial (CC BY-NC 4.0) license, which permits others to distribute, remix, adapt, build upon this work non-commercially, and license their derivative works on different terms, provided the original work is properly cited, appropriate credit is given, any changes made indicated, and the use is non-commercial. See: http://creativecommons.org/licenses/by-nc/4.0/.

\section{ORCID iDs}

Gedefaw Diress http://orcid.org/0000-0002-8616-0034

Melese Linger Endalifer http://orcid.org/0000-0003-1505-2500

\section{REFERENCES}

1 McLean E, Cogswell M, Egli I, et al. Worldwide prevalence of anaemia, who vitamin and mineral nutrition information system, 1993-2005. Public Health Nutr 2009;12:444-54.

2 WHO/CDC. Worldwide prevalence of anemia 1993-2005: who global database on anemia. Geneva, Switzerland: World Health Organization, 2008.

3 Haidar J. Prevalence of anaemia, deficiencies of iron and folic acid and their determinants in Ethiopian women. J Health Popul Nutr 2010;28:359.

4 Haidar JA, Pobocik RS. Iron deficiency anemia is not a rare problem among women of reproductive ages in Ethiopia: a community based cross sectional study. BMC Hematol 2009;9:7.

5 Haidar J, Muroki NM, Omwega AM, et al. Malnutrition and iron deficiency in lactating women in urban slum communities from Addis Ababa, Ethiopia. East Afr Med J 2003;80:191-4.

6 De Benoist B, Cogswell M, Egli I. Worldwide prevalence of anaemia 1993-2005. WHO Global Database of anaemia, 2008.

7 World Health Organization. The prevalence of anaemia in women: a tabulation of available information. World Health Organization, 1992.

8 van den Broek NR, Letsky EA. Etiology of anemia in pregnancy in South Malawi. Am J Clin Nutr 2000;72:247S-56.

9 Allen LH. Anemia and iron deficiency: effects on pregnancy outcome. Am J Clin Nutr 2000;71:1280S-4.

10 Targets W. 2025: anaemia policy brief. Geneva: World Health Organization, 2014.

11 Baig-Ansari N, Badruddin SH, Karmaliani R, et al. Anemia prevalence and risk factors in pregnant women in an urban area of Pakistan. Food Nutr Bull 2008;29:132-9. 
12 Ismail IM, Kahkashan A, Antony A. Role of socio-demographic and cultural factors on anemia in a tribal population of North Kerala, India. Int J Community Med Public Health 2017;3:1183-8.

13 White AM, Castle I-JP, Hingson RW, et al. Using death certificates to explore changes in alcohol-related mortality in the United States, 1999 to 2017. Alcohol Clin Exp Res 2020;44:178-87.

14 Hingson RW, Zha W, Weitzman ER. Magnitude of and trends in alcohol-related mortality and morbidity among U.S. college students ages 18-24, 1998-2005. J Stud Alcohol Drugs Suppl 2009;16:12-20.

15 Fuchs CS, Stampfer MJ, Colditz GA, et al. Alcohol consumption and mortality among women. N Engl J Med Overseas Ed 1995;332:1245-50.

16 Djoussé L, Lee I-M, Buring JE, et al. Alcohol consumption and risk of cardiovascular disease and death in women: potential mediating mechanisms. Circulation 2009;120:237.

17 Fletcher LM, Dixon JL, Purdie DM, et al. Excess alcohol greatly increases the prevalence of cirrhosis in hereditary hemochromatosis. Gastroenterology 2002;122:281-9.

18 Looker AC, Dallman PR, Carroll MD, et al. Prevalence of iron deficiency in the United States. JAMA 1997;277:973-6.

19 Ford C, Wells FE, Rogers JN. Assessment of iron status in association with excess alcohol consumption. Ann Clin Biochem 1995;32 (Pt 6:527-31.

20 Moirand R, Lescoat G, Delamaire D, et al. Increase in glycosylated and nonglycosylated serum ferritin in chronic alcoholism and their evolution during alcohol withdrawal. Alcohol Clin Exp Res 1991;15:963-9.

21 Whitfield JB, Zhu G, Heath AC, et al. Effects of alcohol consumption on indices of iron stores and of iron stores on alcohol intake markers. Alcohol Clin Exp Res 2001;25:1037-45.

22 loannou GN, Dominitz JA, Weiss NS, et al. The effect of alcohol consumption on the prevalence of iron overload, iron deficiency, and iron deficiency anemia. Gastroenterology 2004;126:1293-301.

23 Malenganisho W, Magnussen P, Vennervald BJ, et al. Intake of alcoholic beverages is a predictor of iron status and hemoglobin in adult Tanzanians. J Nutr 2007;137:2140-6.

24 Gudeta TA, Regassa TM, Belay AS. Magnitude and factors associated with anemia among pregnant women attending antenatal care in bench Maji, Keffa and Sheka zones of public hospitals, Southwest, Ethiopia, 2018: a cross -sectional study. PLoS One 2019;14:e0225148.

25 Dargie A, Eshetie Y, Aynalem Y. Prevalence of alcohol use during pregnancy and its association with partner alcohol use in East Africa: systematic review and meta-analysis 2019.

26 Lewis G, Wise MP, Poynton C, et al. A case of persistent anemia and alcohol abuse. Nat Clin Pract Gastroenterol Hepatol 2007;4:521-6.

27 Wakabayashi I. Relationships of habitual alcohol intake with Erythrocyte-Related indices in middle-aged Japanese men. Acta Haematol 2019;142:154-61.

28 Milman N, Pedersen AN. Blood haemoglobin concentrations are higher in smokers and heavy alcohol consumers than in nonsmokers and abstainers: should we adjust the reference range? Ann Hematol 2009;88:687-94

29 Berhe B, Mardu F, Legese H, et al. Prevalence of anemia and associated factors among pregnant women in Adigrat General Hospital, Tigrai, Northern Ethiopia, 2018. BMC Res Notes 2019;12:310.

30 Woldegebriel AG, Gebregziabiher Gebrehiwot G, Aregay Desta $A$, et al. Determinants of anemia in pregnancy: findings from the Ethiopian health and demographic survey. Anemia 2020;2020:2902498.

31 Obse N, Mossie A, Gobena T. Magnitude of anemia and associated risk factors among pregnant women attending antenatal care in Shalla Woreda, West Arsi zone, Oromia region, Ethiopia. Ethiop J Health Sci 2013;23:165-73.

32 Weldekidan F, Kote M, Girma M, et al. Determinants of anemia among pregnant women attending antenatal clinic in public health facilities at Durame town: unmatched case control study. Anemia 2018;2018:8938307.
33 Ebuy Y, Alemayehu M, Mitiku M, et al. Determinants of severe anemia among laboring mothers in Mekelle City public hospitals, Tigray region, Ethiopia. PLoS One 2017;12:e0186724.

34 Haidar J, Nekatibeb H, Urga K. Iron deficiency anemia in pregnant and lactating mothers in rural Ethiopia. East Afr Med $J$ 1999;76:618-22.

35 Berhe K, Fseha B, Gebremariam G, et al. Risk factors of anemia among pregnant women attending antenatal care in health facilities of eastern zone of Tigray, Ethiopia, case-control study, 2017/18. Pan Afr Med J 2019;34:121.

36 Central StatisticalAgency (CSA)[Ethiopia], ICF. Ethiopia Demographic and Health Survey(EDHS), 2016

37 WHO. Iron deficiency anaemia: assessment, prevention, and control. A guide for programme managers. Geneva: WHO, 2001.

38 Asresie MB, Fekadu GA, Dagnew GW. Determinants of anemia among children aged 6-59 months in Ethiopia: further analysis of the 2016 Ethiopian demographic health survey. Adv Public Health 2020;2020:1-6.

39 Ntenda PAM, Chuang K-Y, Tiruneh FN, et al. Multilevel analysis of the effects of Individual- and community-level factors on childhood anemia, severe anemia, and hemoglobin concentration in Malawi. $J$ Trop Pediatr 2018;64:267-78.

40 UNICEF \& World Health Organization. WHO/UNICEF joint monitoring programme for water supply, sanitation and hygiene (JMP), 2017.

41 Mazzanti R, Srai KS, Debnam ES, et al. The effect of chronic ethanol consumption on iron absorption in rats. Alcohol Alcohol 1987;22:47-52

42 Lieb M, Palm U, Hock B, et al. Effects of alcohol consumption on iron metabolism. Am J Drug Alcohol Abuse 2011;37:68-73.

43 Lieber CS. Medical and nutritional complications of alcoholism: mechanisms and management: Springer Science \& Business Media, 2012.

44 Sahle S. Ba Gashe the microbiology of Tella fermentation. SINET: Ethiop J Sci 1991:14:81-92.

45 Bahiru B, Mehari T, Ashenafi M. Chemical and nutritional properties of'tej' an Indigenous Ethiopian honey wine: variations within and between production units. Journal of Food Technology in Africa 2001;6.

46 Bacha K, Mchari T, Ashenafi M. Microbiology of the fermentation of shamita, a traditional Ethiopian fermented beverage. SINET: Ethiopian Journal of Science 1999;22:113-26.

47 Baye K. Teff: nutrient composition and health benefits, 2014.

48 Yohannes T, Melak F, Siraj K. Preparation and physicochemical analysis of some Ethiopian traditional alcoholic beverages. African Journal of Food Science 2013;7:399-403.

49 Lee M, Regu M, Seleshe S. Uniqueness of Ethiopian traditional alcoholic beverage of plant origin, Tella. Journal of Ethnic Foods 2015;2:110-4.

50 Reale A, Konietzny U, Coppola R, et al. The importance of lactic acid bacteria for phytate degradation during cereal dough fermentation. $J$ Agric Food Chem 2007;55:2993-7.

51 Pranoto Y, Anggrahini S, Efendi Z. Effect of natural and Lactobacillus plantarum fermentation on in-vitro protein and starch digestibilities of sorghum flour. Food Biosci 2013;2:46-52.

52 Sripriya G, Antony U, Chandra TS. Changes in carbohydrate, free amino acids, organic acids, phytate and $\mathrm{HCl}$ extractability of minerals during germination and fermentation of finger millet (Eleusine coracana). Food Chem 1997;58:345-50.

53 Thoma Eet al. Changes of some blood count variables in correlation with the time of alcohol abuse. J Addict Res Ther 2015;06:221.

54 Berad A, Chand V. Study to compare hematological parameters in alcoholic and non-alcoholic individuals. Natl J Physiol Pharm Pharmacol 2019;9:1-9.

55 Akanni EO, Mabayoje VO, Zakariyahu TO, et al. Haematological characterization among heavy alcohol consumers in Osogbo Metropolis. Res J Med Sci 2010;4:48-52.

56 Rubina M, RB KB, MS TK. A comparative study on hematological parameters among the social and problem drinkers admitted in a tertiary care rehabilitation centre. International Journal of Research in Medical Sciences 2019;7:2981. 